\title{
A DUPLA MARGINALIDADE DE JOSÉ DE ACOSTA: RELIGIÃO E SOBERANIA NO VICE-REINO DO PERU (SÉC. XVI)
}

\author{
Victor Santos Vigneron de La Jousselandière \\ Graduado em História pela Universidade de São Paulo; \\ mestrando em História Social pela Universidade de São Paulo
}

\begin{abstract}
Resumo
Com este artigo procura-se refletir sobre o estatuto conferido à alteridade extra-europeia na obra do jesuíta castelhano José de Acosta. Por um lado, tal análise permite destacar alguns usos da "religião" como instrumento de compreensão das populações "bárbaras"; por outro lado, trata-se de apontar para o nexo existente entre o projeto evangelizador e a instituição de uma soberania castelhana sobre o Vice-Reino do Peru, na segunda metade do século XVI.
\end{abstract}

Pallavras-chave

José de Acosta • religião • soberania.

\section{Correspondência}

Rua Altino Rosa de Moraes, $\mathrm{n}^{\circ} 69$ - apto. 3

Vila Mariana - São Paulo - SP

CEP 04121-060

E-mail: victor.jousselandiere@usp.br

* Este artigo é resultado de um percurso de investigação que conta com o reconhecimento institucional da Fundação de Amparo à Pesquisa do Estado de São Paulo; se bem que as reflexões a seguir não sejam consequência mecânica do financiamento obtido, expresso o merecido reconhecimento a esse órgão público de fomento à pesquisa. Em sentido diverso, agradeço ainda às considerações feitas à minha pesquisa por parte dos professores Carlos Alberto de Moura Ribeiro Zeron, Eduardo Natalino dos Santos e Antonella Romano. Finalmente, manifesto minha profunda gratidão para com o professor Adone Agnolin, sob cuja orientação se desenvolve meu mestrado em História Social. Seja como for, de acordo com a fórmula consagrada, responsabilizo-me inteiramente pelo conteúdo deste artigo. 


\title{
THE DOUBLE MARGINALITY OF JOSÉ DE ACOSTA: RELIGION AND SOVEREIGNITY AT THE VICEROYALTY OF PERU (SIXTEENTH CENTURY)
}

\author{
Victor Santos Vigneron de La Jousselandière \\ Graduated in History by the Universidade de São Paulo; Student of master's degree \\ in Social History by the Universidade de São Paulo.
}

\begin{abstract}
The purpose of this article is to reflect on the status given to non European otherness in the work of the castilian Jesuit José de Acosta. This analyzes allow us to highlight some uses of "religion" as a tool for understanding the natives; furthermore, it aims at emphasizing the link between the evangelizing project and the instituition of a Castilian sovereignty over the vice royalty of Peru, in the second half of sixteenth century.
\end{abstract}

Keywords

José de Acosta • religion • sovereignty

\section{Contact}

Rua Altino Rosa de Moraes, $\mathrm{n}^{\circ} 69$ - apto. 3

Vila Mariana - São Paulo - SP

CEP 04121-060.

E-mail: victor.jousselandiere@usp.br

* This article is the result of a research project that has the institutional recognition of the Foundation for Research Support of São Paulo; thought the following reflections are not mechanical consequence of the funding obtained, I express the deserved acknowledgment for this public agency for research support. In a different way, I thank the statements made to my work by professors Carlos Alberto de Moura Ribeiro Zeron, Eduardo Natalino dos Santos e Antonella Romano. Finally, I express my deep gratitude to professor Adone Agnolin, under whose guidance I develop my master in Social History. Anyway, according to the formula established, I take full responsibility for the content of this article. 


\section{Introdução}

Uma rica historiografia dedicou-se a analisar os esforços operados para compreender o Novo Mundo em termos familiares à civilização cristã. ${ }^{1}$ Ora, tal interesse não é secundário. Efetivamente, o aparecimento daquela região no horizonte geográfico e cultural europeu teve desdobramentos fundamentais. Isso porque as notícias que chegavam das regiões mais apartadas do mundo evidenciaram então a necessidade de ajustar o conhecimento tradicional às novas problemáticas trazidas pelos viajantes. No que se refere especificamente à América, o que se viu foi a constituição de um laboratório privilegiado de ressignificação dos conteúdos culturais europeus.

Tendo isso em vista, talvez não seja excessivo sugerir que a obstinada instabilidade do Novo Mundo invista a crise de um papel constitutivo nos contextos coloniais ibéricos. Seja como for, é justamente enquanto passagem crítica que tem lugar o processo de inclusão das diferenças extra-europeias no interior da cultura ocidental. Por um lado, a "invenção da América" não supõe uma criação ex nihilo: trata-se antes de uma inventio no sentido latino, isto é, de uma reorganização a partir do acervo pré-existente com vistas à definição de uma nova realidade. ${ }^{2}$ Ao mesmo tempo, o caráter necessariamente tradicional dos códigos utilizados para denotar a alteridade não impede uma sua generalização que permita adequá-los a realidades imprevistas. ${ }^{3}$ A inclusão da diferença no interior de uma linguagem familiar ao horizonte cultural europeu confere identidade à civilização cristã; ao longo desse processo, caracterizado pelo incessante exercício de redefinição de fronteiras, igualdade e diferença são marcadas enquanto objetos irredutíveis e inseparáveis.

Mas, não obstante o desafio representado pelo Novo Mundo, o tema conheceu um impacto imediato ao menos incerto nos ambientes intelectuais europeus. ${ }^{4}$ Analisar os artífices desse conhecimento da alteridade não significa, contudo, dar-se com um problema marginal. Muito pelo contrário, é o incerto limiar das

1 Cf. especialmente GLIOZZI, Giuliano. Adam et le Nouveau Monde. La naissance de l'anthropologie comme idéologie coloniale: des généalogies bibliques aux théories raciales (1500-1700). Lecques: Thééthète Éditions, 2000 [1977].

2 O'GORMAN, Edmundo. La invención de América: investigación acerca de la estructura histórica del Nuevo Mundo y del sentido de su devenir. México: Fondo de Cultura Económica, 2003 [1958]. Tampouco se trata de uma "invenção" absolutamente intelectual; fato que se procurará explicitar dentro do recorte proposto a seguir, as categorias explicativas encontram-se profundamente associadas aos diversos projetos imperiais. GLIOZZI, Giuliano, op. cit., p. 11-20.

3 GASBARRO, Nicola Maria. Missões: a civilização cristã em ação. In: MONTERO, Paula (org.). Deus na aldeia: missionários, índios e mediação cultural. São Paulo: Globo, 2006, p. 67-109.

4 ELLIOTT, John Huxtable. The Old World and the New: 1492-1650. Cambridge: Cambridge University Press, 1970, p. 28-53. 
situações de fronteira que impõe às figuras que ali se encontram a tarefa de adequar instâncias centrais da tradição ocidental às particularidades de cada contexto. Com relação a isso, a missão aparece como instituição privilegiada a atuar nesse âmbito, no mais das vezes descontínuo, onde se dá o exercício de especificação do quadro categorial recebido da tradição. Diferentemente, contudo, de recuperar o cristianismo enquanto "fenômeno total", trata-se de retomar o percurso histórico que incide na constituição de uma civilização "estruturalmente missionária", na qual se observa a progressiva generalização dos conteúdos que lhe são próprios ("religião", "direito" etc.). ${ }^{5}$ Identificar os atores que tomaram parte nesse processo e mapear suas relações de proximidade e de divergência, são tarefas fundamentais para que se tenha um quadro operativo que enriqueça a análise do encontro entre europeus e suas alteridades. Caso particularmente interessante nesse sentido é oferecido pelo jesuíta castelhano José de Acosta.

\section{A linguagem da idolatria}

\subsection{As outras linguagens}

Acosta é correntemente descrito com referência ao seu caráter "melancólico". Contudo, para além de qualquer consideração que se esgote na positividade médica do epíteto (isto é, na identidade fenomênica de um eventual diagnóstico), importa recuperar a historicidade dessa categoria. Tal procedimento permite analisar o epíteto em questão à luz do regime de racionalidade próprio à medicina galênica, cuja concepção holística, centrada no "equilíbrio dos humores", estabelece uma íntima associação entre a compleição orgânica do indivíduo e seu caráter moral. No que toca especificamente à melancolia, trata-se de uma caracterização então associada ao pendor intelectual, o que permite recuperar desde já alguns traços fundamentais que marcaram a atuação de Acosta no interior da Companhia de Jesus. ${ }^{6}$

Nascido em 1540 e engajado desde jovem nos colégios inacianos da Península Ibérica, Acosta percorreu todas as etapas do trivium com algum destaque, de modo a tornar-se professor de teologia. ${ }^{7}$ Mas se sua atividade docente concorre para

5 GASBARRO, Nicola Maria, op. cit., p. 71.

6 Carente de análises biográficas abrangentes, a trajetória de Acosta será referida aqui com base na síntese elaborada por Edmundo O'Gorman. O'GORMAN, Edmundo. Prólogo. In: ACOSTA, José de. Historia natural y moral de las Indias. En que se tratan de las cosas notables del cielo, elementos, metales, plantas y animales dellas y los ritos, y ceremonias, leyes e gobierno de los indios. México: Fondo de Cultura Económica, 2006 [1962], p. XV-CXI.

7 Tratava-se então do sistema de organização de disciplinas mais valorizado nos colégios jesuítas, 
explicar a inserção nas suas obras das discussões teológico-jurídicas da época, a trajetória desse jesuíta perderia em inteligibilidade se analisada separadamente das funções administrativas por ele exercidas. Ora, esse dado é fundamental para que se compreenda o envio de Acosta ao Vice-Reino do Peru, onde restará por mais de dez anos a organizar a recém-instalada missão jesuítica (1567). ${ }^{8} \mathrm{De}$ volta à Europa (após uma breve porém importante temporada na Nova Espanha), o jesuíta assumiu um papel de relevo nas disputas de poder que vinham sendo travadas entre a Coroa de Castela e o Generalato da Companhia em Roma. Até sua morte, em 1600, Acosta ainda ocupou alguns cargos de relevo nas províncias ibéricas da Companhia de Jesus. ${ }^{9}$ Já esses poucos dados biográficos dão conta da "dupla marginalidade" que caracteriza a trajetória dessa personagem: por um lado, trata-se de um missionário que, na América, pouco se envolveu diretamente com atividades evangelizadoras, ocupando-se mais amiúde com questões organizativas e teológicas, ${ }^{10}$ por outro lado, trata-se de um autor que, a despeito de sua rica fortuna editorial, dirigiu-se àquele restrito público ocupado com o tema americano, de modo a distar bastante do centro em torno do qual gravitava a intelectualidade jesuítica de sua época. ${ }^{11}$ De maneira inversa, porém, é possível reivindicar a riqueza dessa marginalidade de Acosta, que lhe permitiu conjugar a experiência dos desafios impostos pela novidade americana (potencializada pelo acesso a farto material produzido por terceiros) junto ao trabalho de sistematização e de reelaboração "do" e "no" quadro categorial europeu.

Publicada inicialmente em 1590, a Historia natural y moral de las Indias deve ser inserida nos quadros dessa "dupla marginalidade" de Acosta. ${ }^{12}$ Logo no Proêmio, o autor adverte que a novidade de sua obra reside no fato de ali estarem conjugadas descrição histórica e considerações filosóficas. ${ }^{13}$ Já a partir dessa afirmação é possível comparar a Historia general y natural de las Indias, islas y tierra firme del mar océano (1535), de Gonzalo Fernández de Oviedo y

fato que será refletido na elaboração da Ratio Studiorum (1599).

8 Durante boa parte do período peruano (1571-1586), Acosta ocupou a função de reitor do Colégio de Lima (1575-1586), chegando a dirigir a província por alguns anos (1576-1581).

9 Foi visitador das províncias de Andaluzia (1589-1590) e de Aragão (1590-1591), preposto da Casa Professa de Valladolid (1592-1596) e reitor do Colégio de Salamanca (1597-1600).

${ }^{10}$ O próprio Acosta credita ao teólogo (enquanto especialista encarregado de dirimir eventuais dúvidas sobre a doutrina) um papel subsidiário na missão. ACOSTA, José de. De procuranda Indorum salute. Madri: Consejo Superior de Investigaciones Cientificas, 1984-1987 [1588], v. 2, p. 90-95.

${ }^{11}$ A título de exemplo confira-se a discreta presença do tema americano (possivelmente lido a partir de Acosta) na suma bibliográfica produzida pelo também jesuíta Antonio Possevino, a Bibliotheca selecta (1593).

${ }^{12}$ Para facilitar a leitura, essa obra será sempre referida como Historia.

${ }^{13}$ ACOSTA, José de. Historia, op. cit., p. 13. 
Valdés, com a obra de Acosta. Ocorre que, ao contrário de Oviedo, este oferece um quadro sistemático de compreensão do fenômeno americano nas suas diversas manifestações. ${ }^{14}$ Tal comparação sugere que se pense a obra de Acosta nos quadros de uma "história total", que ultrapassaria a descrição imediata do fenômeno americano para inquirir suas causas essenciais. Sintoma desse caminho trilhado pelo autor é sua complexa relação com a tradição e com a experiência: embora atribua estatuto de verdade à observação, o que inclusive concorreria para uma maior sensibilidade à diversidade etnológica americana, não é possível falar simplesmente numa "modernidade empirista" que supostamente teria caracterizado o autor. Ora, sua respeitosa reivindicação da auctoritas dos Antigos e da Patrística não deixa lugar a dúvidas: existem limites claros além dos quais a experiência e a dedução (a "imaginação") não têm lugar. Assim, a abertura crítica proporcionada pela valorização da observação volta-se muito mais contra a má utilização do acervo filosófico-teológico tradicional. É dessa forma que se pode compreender, por exemplo, que sua crítica à Meteorologia aristotélica não ofereça qualquer desafio central à sua Física $;{ }^{15}$ trata-se antes de corrigir as implicações práticas da tradição numa situação por ela imprevista.

Da mesma maneira, o movimento que procura reelaborar a tradição (generalizar suas implicações) atende à necessidade de sistematização da novidade americana. O percurso descritivo adotado na Historia é exemplar com relação a isso. Os quatro livros iniciais dessa obra procuram sistematizar a descrição acerca do aspecto "natural" do Novo Mundo a partir de sua inclusão no quadro "aristotélico" de ordenação dos elementos. ${ }^{16}$ Dessa forma, ao enquadramento proporcionado pelos quatro "elementos puros" (terra, fogo, ar e água), seguem-se suas combinações (minerais, vegetais e animais), numa organização hierárquica dos entes terrestres cuja figura superior é o homem, tema dos três livros finais. ${ }^{17}$ A descrição feita opera assim com base numa "redução" teórica do Novo Mundo a esse quadro conceitual, que tem na analogia um instrumento privilegiado. Essa inclusão de uma situação nova no acervo cognitivo tradicional (devidamente reelaborado para compreendê-la) confere não apenas familiaridade ao fenômeno americano, como também funda uma "unidade elementar" entre Novo e Velho Mundo. Qualquer distinção qualitativa que incorra numa clivagem radical entre

\footnotetext{
${ }^{14}$ PAGDEN, Anthony. The fall of natural man: the American Indian and the origins of comparative ethnology. Cambridge: Cambridge University Press, 1999 [1982], p. 151-152.

15 ACOSTA, José de. Historia, op. cit., p. 35-40.

${ }^{16}$ Caberia analisar a tradição aristotélica à qual Acosta estaria mais proximamente ligado, tendo em vista talvez os colégios que frequentou, especialmente o de Medina del Campo.

${ }^{17}$ O'GORMAN, Edmundo. Prólogo, op. cit., p. XLV-LIII.
} 
essas realidades fica assim abolida, de modo que as diferenças passam a se explicar em termos quantitativos, sendo, pois, comparáveis. Essa comparabilidade no plano natural abre-se à comunicabilidade no interior da humanidade.

"Bárbaro" é o termo utilizado por Acosta para definir as populações extraeuropeias. Embora o significante esteja em continuidade com os demais autores que escreveram sobre o tema, é importante notar que o significado encontra-se nessa época em processo de modificação. O que então se verifica é a progressiva passagem de uma distinção insuperável para um conceito de "bárbaro" que define um grau possível de comunicação. ${ }^{18}$ Toda a alteridade encontra-se, nessa perspectiva, inserida no interior da humanidade, ao passo que toda diversidade é "reduzida" a graus de civilização. De modo análogo ao que fora realizado no plano natural, frente à percepção da diversidade representada pelo Novo Mundo, Acosta opera uma sistematização num quadro categorial ampliado. No limite, portanto, sua classificação dos três graus de barbarismo está apta a compreender todas as situações encontradas nas Índias, sejam elas Ocidentais, Orientais ou internas à civilização cristã. Identificar os critérios que compõem essa classificação permite formular uma imagem mais complexa da construção dessa linguagem denotativa da alteridade pelo Ocidente. ${ }^{19}$

Dentre tais critérios a linguagem aparece como elemento fundamental. ${ }^{20} \mathrm{Sem}$ tornar absoluta a (variável) classificação oferecida por Acosta, importa recuperar alguns momentos de sua explicitação no texto que parecem fundamentais à construção de seu sentido. Sendo assim, de imediato, mostra-se de grande interesse a forma (estranha à primeira vista) pela qual a descrição das sociedades chinesas (mais alto grau de "civilização na barbárie") é inserida na História. Tal estranhamento advém do fato de a estrutura toda dessa obra privilegiar a descrição das populações mexicas e incas (agrupadas no grau intermediário de barbárie), cujas tradições são apontadas pormenorizadamente nos livros sexto e sétimo. ${ }^{21}$ A despeito dessa circunscrição do tema, contudo, Acosta inicia o livro sexto com um capítulo intitulado Que es falsa la opinión de los que tienen a los indios por

${ }^{18}$ AGNOLIN, Adone. Jesuitas e selvagens: a negociação da fé no encontro catequético-ritual americano-tupi (séculos XVI-XVII). São Paulo: Humanitas; Fapesp, 2007, p. 430-473.

${ }^{19}$ Importante destacar a essa altura que o presente texto não tem por objetivo analisar os impasses efetivos colocados pelas populações nativas à ação europeia, tema sem dúvida interessante, mas que foge aos interesses deste trabalho. A presença da alteridade aparece aqui de forma apenas especular à ação missionária, de modo a exigir desta uma série de respostas. É a construção e a operação dessas "respostas", fundamentais à identidade ocidental, que importa retomar aqui.

${ }^{20}$ ACOSTA, José de. De procuranda, op. cit., v. 1, p. 62-63.

${ }^{21}$ ACOSTA, José de. Historia, op. cit., p. 313-421. 
hombres faltos de entendimiento, ao qual se sucedem nove capítulos onde se realiza uma discussão sobre a escrita dos variados povos bárbaros. ${ }^{22}$ Ora, não é secundário que o tema da escrita seja introduzido exatamente pela referência ao caso chinês. ${ }^{23}$ Nesse sentido, e perante a forte impressão deixada por esse contexto missionário, Acosta procura reconduzir a escrita chinesa a um território ágrafo ou apenas imperfeitamente gráfico. ${ }^{24}$ Tal imperfeição adviria do caráter ideogramático e não-silábico da escrita chinesa, que poderia ser chamada mais apropriadamente de "pintura" ou "cifra" ${ }^{25}$ A diferença aqui reside no fato de que uma escrita silábica teria uma maior capacidade de apreensão de realidades imprevistas; nessa perspectiva, a impossibilidade por parte dos ideogramas chineses de referir nomes desconhecidos apontaria para uma limitação fundamental dessa linguagem. Todavia, a inserção do exemplo chinês aqui não é menos importante. A distinção operada entre esse grau de barbárie com relação aos demais residiria principalmente, segundo Acosta, na existência dessa "escrita balbuciante", signo de uma condição civil notadamente desenvolvida. ${ }^{26} \mathrm{E}$, como consequência dessa proximidade a um ideal de civilização, a proposta missionária sugerida por Acosta é emblemática quando aponta para a necessidade de diálogo: trata-se ali de converter na base do puro convencimento. ${ }^{27}$

A passagem para o contexto peruano e mexicano permite notar algumas questões que são apenas entrevistas quando da descrição do âmbito chinês. Se aí fica claro que Acosta toma partido numa disputa ainda não resolvida acerca da escrita chinesa, no que se refere àquelas populações americanas de "barbarismo médio", o jesuíta parte já da clara pressuposição acerca da ausência de escrita. Com relação ao contexto mesoamericano, a História apresenta os glifos mexicas como "pinturas", na esteira de seu informante, o também jesuíta Juan de Tovar, que, por seu turno, inspirou-se grandemente para composição de seus escritos na

${ }^{22}$ Idem, p. 313-327.

${ }^{23}$ Idem, ibidem, p. 318-322.

${ }^{24}$ São três os autores referidos por Acosta no que se refere ao contexto oriental. Em primeiro lugar, são abundantes as referências às cartas de Francisco Xavier, que refletem uma visão ainda muito indireta da missão chinesa; além disso, há referência a Cosme de Torres, primeiro superior da missão jesuítica japonesa; finalmente, Acosta travou um importante contato com o também jesuíta Alonso Sánchez, missionário atuante nas Filipinas. Com relação a esta última figura, é interessante ter em mente sua proposta de invasão da China, entendida como forma de conversão da região; tal proposta suscitou uma viva oposição da parte do geral da Companhia, Cláudio Acquaviva, que encarregou Acosta de escrever uma refutação.

${ }^{25}$ ACOSTA, José de. Historia, op. cit., p. 322-324.

${ }^{26}$ ACOSTA, José de. De procuranda, op. cit., v. 1, p. 62-63.

${ }^{27}$ Idem, v. 1, p. 62-63. 
obra do dominicano Diego Durán. ${ }^{28}$ Por outro lado, ainda entre os mexicanos, o grande desenvolvimento da capacidade mnemônica (fato ligado à particularidade dos códices mexicas, ignorada por Acosta) facultaria a estes a capacidade de fixação de algum passado, ainda que não muito recuado. ${ }^{29} \mathrm{Já}$ com relação ao Peru, o autor destaca a existência dos quipus, entendidos como artifício através do qual os nativos teriam conseguido exercer um controle contabilístico da produção no vasto território controlado pelo Inca. ${ }^{30}$ Aqui especificamente, o tema da escrita e da fixação dos conteúdos encontra-se grandemente associado à existência de um governo; o controle proporcionado pelo quipu, ainda que artificioso e limitado enquanto meio, seria indicador de algum desenvolvimento por parte dos nativos na medida em que facultaria ao Inca o trabalho de controle sobre os tributos. Seja como for, fica implícita aqui a ideia de que a existência de leis invariáveis (espécie de "segurança jurídica") encontrar-se-ia profundamente associada à presença de escrita. ${ }^{31}$

Mas o conceito de "bárbaro", quando se refere àquelas populações que se encontrariam num grau mais baixo de civilização, encontra-se diretamente ligado à ideia de "selvagem", ${ }^{32}$ Para esse caso, Acosta não identifica qualquer artifício mais ou menos próximo à escrita, mas apenas a fala como forma de comunicação. Assim, embora asseguradas no interior da humanidade, tais populações são apresentadas como extremamente falhas na sua capacidade comunicativa. Além de ágrafas, a própria pobreza vocabular das línguas selvagens é apresentada como indício de sua compleição rude. Novamente, revela-se aqui a íntima associação entre comunicação e vida civil, na medida em que as ausências vocabulares identificariam a inexistência de instituições básicas da vida social. Ora, o fato de os nativos não possuírem, nas suas variadas línguas, uma palavra para denotar "deus", apontaria justamente nesse sentido. ${ }^{33}$ Em situações extremas, são populações em

${ }^{28}$ SANTOS, Eduardo Natalino dos. Deuses do México indigena: estudo comparativo entre narrativas espanholas e nativas. São Paulo: Palas Athena, 2002, p. 169. É possível que Acosta tenha tido acesso a algum códice mexica quando de sua estada em Roma.

${ }^{29}$ ACOSTA, José de. Historia, op. cit., p. 70-72.

${ }^{30}$ Idem, p. 324-326. Os quipus são uma das poucas manifestações nativas aceitas pela igreja peruana após a "virada ortodoxa" da década de 1590, tendo sido inclusive recuperados como sistema de contabilidade de pecados por ocasião da confissão. ESTENSSORO FUCHS, Juan Carlos. Del paganismo a la santidad. La incorporación de los indios del Perú al catolicismo. 1532-1750. Lima: Instituto Francés de Estudios Andinos; Instituto Riva-Aguero, 2003 [1998], p. 217-223.

${ }^{31}$ ACOSTA, José de. De procuranda, op. cit., v. 1, p. 62-65.

${ }^{32}$ Trata-se de uma categoria que muda a depender da obra em questão. No De procuranda inclui apenas as populações nômades sem chefias, como os chichimecas (norte da Nova Espanha), os índios "brasis" etc.; já na Historia inclui também os "mais civilizados" araucanos (Chile), os quais possuiriam uma vida comum sob alguma chefia.

${ }^{33}$ ACOSTA, José de. Historia, op. cit., p. 245-247. 
que mesmo a capacidade de enunciação encontrar-se-ia obstada pela vida solitária em cavernas ou em florestas, longe da comunidade. Ora, se o desenvolvimento da vida civil no contexto chinês permitiria ali uma "conversão pelo convencimento", a condição selvagem dessas populações exige que se proceda a um trabalho prévio de civilização, operação que combata a instabilidade desses grupos, no mais das vezes nômades e isolados. É nesse sentido que deve ser compreendido o processo de "gramatização" das línguas nativas (paralelo à "redução" urbana dos índios em aldeamentos), que permitiria sua fixação linguística a partir da qual o exercício comunicativo seria realizado sobre bases mais sólidas. ${ }^{34}$ Da mesma forma, o patrocínio das línguas-gerais (quéchua e aymara no caso peruano e nahuatl no caso mexicano) é sugerido por Acosta como forma de padronização linguística que não perdesse de vista algum enraizamento nas instituições nativas. ${ }^{35}$

Pelo que se viu, portanto, as linguagens outras jogam um papel fundamental na construção dessa imagem do outro, de modo que aquele seu grau de imperfeição é ainda assim reconduzido à comunicabilidade essencial relativa à condição humana das populações bárbaras. Signo de uma compleição mais ou menos civil, a comunicação permitiria ainda a conservação de uma memória comum, falha entre os americanos. A ausência da memória que, no mais das vezes, remeteria a quatrocentos anos, é diretamente relacionada por Acosta à ausência de uma escrita que fixasse os acontecimentos. A linguagem do outro, ineficaz enquanto meio de comunicação de significados, também o é enquanto meio de rememoração e de fixação de conteúdos comuns. Tal fato adquire relevo quando se pensa que a Historia enquadra as populações extra-europeias no interior de uma genealogia bíblica do homem que remete necessariamente a Noé e a Adão. Essa frágil memória e o consequente esquecimento desse passado comum são elementos importantes na economia da explanação operada por Acosta. Isso porque a instabilidade constitutiva das populações bárbaras (desregrada na língua como nos costumes) abriria a possibilidade de se pensar o esquecimento do passado como indício de uma historicidade na qual ficaria prevista, implicitamente, a possibilidade de degeneração dos povos. Numa "imagem do outro" própria de Acosta, as "linguagens outras" não jogariam um papel fundamental apenas para definir aquilo que deve ser corrigido (o que sua significação falha não permitiria expressar "deus"); é importante reter ainda o significado central que seu obs-

\footnotetext{
${ }^{34}$ Com relação ao processo de "gramatização" das línguas nativas, cf. AGNOLIN, Adone, op. cit.

${ }^{35}$ É interessante pensar a posição de Acosta no debate promovido nos domínios de Castela com relação à "hispanização" dos povos conquistados. Se, por um lado, Acosta mostra-se favorável ao ensino do castelhano, ainda assim releva a importância das línguas-gerais nativas.
} 
tinado esquecimento tem para a definição de uma humanidade mesma, apenas acidentalmente (historicamente) diversa.

\subsection{A linguagem da idolatria}

Os graus de barbarismo sugeridos por Acosta não têm sua base, contudo, num único critério. Pelo contrário, os três livros finais da Historia contemplam uma série de traços civilizacionais que, no seu conjunto, compõem o quadro operativo a partir do qual Acosta desdobra o tema da alteridade antropológica. Se o dado linguístico permite uma leitura privilegiada acerca da inserção do outro na genealogia bíblica, ele não pode ser tomado como critério unívoco a definir a pertença a um determinado grau de civilização. Sendo assim, é bastante sugestivo que o tema moral seja introduzido a partir da descrição das "religiões" nativas, apresentadas nas suas insuficiências idolátricas e supersticiosas.

Mais precisamente, o livro quinto da Historia inicia-se com a apresentação da figura diabólica, topos constante da literatura missionária. ${ }^{36} \mathrm{O}$ Diabo, contudo, não se reveste aqui de uma função puramente retórica; pelo contrário, essa personagem entra em cena munida de um papel decisivo para argumentação de Acosta. Marcado indelevelmente por sua queda, o Diabo age de modo a interporse entre os homens e Deus, com o objetivo de tornar este último opaco perante os primeiros. Tal "ação negativa" concorre para explicar o estado de coisas no Novo Mundo, sua instabilidade crônica e, principalmente, sua religião idolátrica. Dessa maneira, a explicação fornecida por Acosta torna familiares as insuficiências indígenas, que passam a ser reconduzíveis ao acervo epistemológico cristão. Efetivamente, aliás, tal interpretação é tributária de uma tradição anterior no Vice-Reino do Peru. Trata-se de um posicionamento que começara a ganhar corpo, em finais da década de 1560, entre um grupo de funcionários reais, em que se destacam as figuras de Juan Polo de Ondegardo, Juan de Matienzo, Pedro Sarmiento de Gamboa e Gregorio González de Cuenca. Sua posição negativa com relação às populações indígenas daria suporte à política de "pacificação" levada a cabo pelo vice-rei Francisco de Toledo (1569-1581). Apenas da década de 1590, especialmente entre jesuítas e seculares, a interpretação demonizante se tornará predominante também na igreja peruana, o que perdurará até meados do século XVII. Nesse período, José de Acosta e Toribio de Mogrovejo (bispo de Lima) jogaram um papel fundamental a favor dessa mudança. ${ }^{37}$

\footnotetext{
${ }^{36}$ ACOSTA, José de. Historia, op. cit., p. 243-245.

${ }^{37}$ ESTENSSORO FUCHS, Juan Carlos. Del paganismo a la santidad, op. cit., p. 179-193.
} 
Em última instância, o isolamento americano permitiria explicar o domínio diabólico sobre a região na base da ignorância (da incomunicabilidade) da verdade revelada. E a ampla difusão das mais variadas formas de idolatria aparece como sintoma incontestável desse "império invertido" praticado pelo Diabo. O ídolo seria seu artifício privilegiado para revestir as criaturas de um impossível poder imanente, de modo que a essência sobrenatural ficasse reduzida à aparência dos fenômenos. ${ }^{38}$ Nesse ponto, a Historia retoma uma importante tradição teológica sobre o conceito de "idolatria" que permite instituir um nexo analógico entre alteridade geográfica (bárbaros) e alteridade histórica (antigos). ${ }^{39}$ Acrescente-se, porém, que a nova realidade encontrada na América exigiu de Acosta uma reelaboração do esquema herdado, de modo que fosse possível abarcar as inéditas idiossincrasias apresentadas pelo fenômeno idolátrico na região. E essa generalização do "código idolátrico" cumpriu um papel fundamental para a elaboração dessa linguagem denotativa do outro. Assim, juntamente com outros traços civilizacionais, a idolatria operou como figura de linguagem privilegiada para "traduzir" a realidade americana em termos inteligíveis. Mais especificamente, a idolatria permitiu englobar o Novo Mundo como "território do religioso", código pressupostamente universal e historicamente generalizado. Resulta disso que o próprio domínio da inteligibilidade conheceu um alargamento; de fato, o exercício da comparação exigiu do acervo cultural europeu a ampliação de seus pressupostos, o que se efetivou através de um conceito de "humanidade" que, paulatinamente, incorporou as diferenças numa base qualitativamente compartilhada.

Essa operação adquire significado quando se analisam os desafios impostos ao conceito de "idolatria" por parte dos graus extremos de barbárie. Assim, no que diz respeito ao contexto chinês, o pouco caso demonstrado pelos mandarins com relação aos ídolos era indício do problema colocado à prática missionária num contexto onde prevaleciam os "ritos civis", e que permitiria uma abertura fundamental à constituição da própria ideia de "ateísmo". ${ }^{40}$ Numa posição oposta, as poucas linhas destinadas na Historia às populações selvagens sugerem o reconhecimento de uma tênue presença de crenças idolátricas entre essas populações; trata-se aqui de uma espécie de "grau zero" do religioso que coloca problemas

\footnotetext{
${ }^{38}$ ACOSTA, José de. Historia, op. cit., p. 243-263.

39 Tradição que remonta ao Livro da sabedoria. GASBARRO, Nicola Maria, op. cit., p. 95. ACOSTA, José de. Historia, op. cit., p. 245.

${ }^{40}$ ACOSTA, José de. Historia, op. cit., p. 321. AGNOLIN, Adone, op. cit., p. 460-473.
} 
igualmente radicais à evangelização, quase que desprovida de seus pressupostos mais essenciais. ${ }^{41}$

O contexto peruano mostra-se particularmente atraente à análise da questão idolátrica na sua especificação local. Tal movimento é realizado preferencialmente através do instrumento privilegiado fornecido pelas huacas. Trata-se, de forma muito sumária, de locais (marcados por uma série de objetos, tais como árvores, pedras, buracos, construções etc.) associados à origem de cada ayllu indígena. Precocemente recuperado enquanto manifestação religiosa de uma específica idolatria nativa, esse termo conhece uma interessante trajetória semântica que o levará a denotar a idolatria na sua acepção mais genérica. ${ }^{42}$ Assim, a trajetória desse termo aponta de forma exemplar para o mecanismo através do qual é operada a generalização de sentido de determinados significantes. As huacas peruanas funcionam, portanto, como índice de uma "religião natural", nos quadros mesmos daquilo que é afirmado por Acosta, isto é, que os índios possuem "algum conhecimento de Deus". ${ }^{43}$ Nesses quadros, a ampliação do número de objetos denotáveis por parte do significante em questão (fato paralelo à sua "naturalização") é simétrica à perda de seu poder de referência direta a realidades concretas. Não é secundário, portanto, o fato de o livro quinto da Historia dedicar-se à descrição das idolatrias e superstições ${ }^{44}$ quase que exclusivamente nos contextos inca e mexica: trata-se justamente de realidades em que o quadro analítico tradicional pode ser operado de uma forma mais confortável (com alguns poucos ajustes) perante a manifestação idolátrica observada nessas regiões. ${ }^{45}$ Aqui se torna possível uma "conversão" propriamente dita, isto é, uma mudança efetivada na base de uma compatibilidade anterior, "religiosa". Nesse sentido específico, a ação diabólica se reveste de outro papel fundamental: trata-se de uma figura necessária enquanto símile negativo de Deus, cuja ação desviante se opera no (e reafirma o) código "religioso" próprio da tradição cristã; trata-se de uma leitura da alteridade operada, enfim, sub specie religionis.

Da mesma forma, o tema da idolatria e das superstições oferece um instrumento adicional para se compreender aquela historicidade identificada anteriormente

\footnotetext{
${ }^{41}$ ACOSTA, José de. Historia, op. cit., p. 358-360.

${ }^{42}$ ESTENSSORO FUCHS, Juan Carlos. Del paganismo a la santidad, op. cit., p. 84-114. Note-se que as obras de Acosta ainda não representam esse processo em seus resultados mais maduros.

${ }^{43}$ ACOSTA, José de. Historia, op. cit., p. 245-247.

${ }^{44} \mathrm{O}$ tema das superstições mereceria uma análise própria, que não será realizada aqui devido aos objetivos específicos desse texto.

${ }^{45}$ O próprio Acosta afirma a relativa facilidade missionária nesses contextos perante outras regiões. ACOSTA, José de. Historia, op. cit., p. 417-421.
} 
na obra de Acosta. Ocorre que, sem solução clara de continuidade com relação à decadência das populações, a ação diabólica, signo por excelência dessa queda, só pode ser pensada nos quadros de uma "genealogia da salvação". Em última instância, a história da humanidade pode ser resumida à disputa entre Deus e o Diabo pelo domínio das almas. Ora, essa disputa tem um sentido claro como não poderia deixar de ser por parte de um missionário: Acosta não deixa de lado um horizonte apocalíptico a coincidir com a extensão do evangelho a todas as partes do mundo ${ }^{46}$ Contudo, o jesuíta rejeita o imediatismo escatológico que marcara as primeiras ondas evangelizadoras peruanas ${ }^{47}$ Assim, com relação àquela aliança restrita (étnica e geograficamente) aos herdeiros de Israel, o advento da revelação neotestamentária significaria um ponto de inflexão a partir do qual o domínio do Diabo se veria progressivamente reduzido. O caráter estruturalmente missionário do quadro civilizacional a partir do qual Acosta atua se faz sentir nessa recuperação da trajetória humana, em que a figura do evangelizador joga um papel central. Com relação à possibilidade de decadência das populações, essa queda encontra-se contida no movimento mais geral em direção ao fim dos tempos. E, dessa forma, questão que fica muito clara no capítulo com o qual Acosta conclui a Historia, a abertura do continente americano ao esforço missionário significaria um passo adiante em direção ao Juízo Final. ${ }^{48}$

No plano terreno, e de forma complementar à ação missionária, o posicionamento adotado pelos funcionários reais concorre igualmente para instituir uma linguagem da alteridade que permita ao império constituir-se, enquanto tal, junto a um território denotável. ${ }^{49}$ É interessante, portanto, pensar na afinidade fundamental existente entre o projeto imperial e o projeto missionário jesuíta no que se refere à definição de uma compatibilidade qualitativa com relação à alteridade, no interior da qual ficariam englobadas as diferenças. ${ }^{50}$ De modo concomitante,

${ }^{46}$ ACOSTA, José de. Historia, op. cit., p. 417-421. É importante referir a publicação, em 1590, dos resumos dos sermões de Acosta, que revelam um teor marcadamente apocalíptico: De Temporibus Novissimus e De Christo Revelato.

${ }^{47}$ Essa reação contra o grupo identificado com a primeira evangelização não é própria de Acosta, mas deve ser compreendida no âmbito das disputas travadas no seio do clero peruano, marcado desde a década de 1560 pelo reforço da Companhia de Jesus e dos padres seculares, em detrimento de franciscanos, dominicanos e agostinianos. ESTENSSORO FUCHS, Juan Carlos. Del paganismo a la santidad, op. cit., p. 184-193.

${ }^{48}$ ACOSTA, José de. Historia, op. cit., p. 417-421.

${ }^{49}$ Importante notar que a principal referência utilizada por Acosta com relação ao contexto peruano é a do já referido funcionário real Polo de Ondegardo.

${ }^{50}$ As inúmeras divergências entre as personagens religiosas e os funcionários reais parecem aterse antes à especificação quantitativa dessa diferença. COELLO DE LA ROSA, Alexandre. Más allá del Incario: imperialismo e historia em José de Acosta, SJ (1540-1600). In: Colonial Latin 
portanto, à instituição de uma soberania territorial sobre uma região volúvel, tratase de instituir igualmente uma "pensabilidade" do outro, finalmente definido em termos estáveis (portador de "religião/idolatria", de "linguagem" etc.).

\section{Tirania honesta}

\subsection{A queda do homem natural}

A inserção da Historia nos debates teológico-jurídicos que vinham sendo travados à época de sua publicação não esgota a riqueza das obras de Acosta. De fato, e esse foi o esforço de evidenciação dos itens anteriores, o autor operou um papel fundamental (dada a sua privilegiada condição "duplamente marginal") no trabalho de reelaboração do acervo cognitivo herdado pela tradição frente à novidade sino-americana. Contudo, é importante notar que seu esforço "totalizante" de sistematização se refere, de forma apenas mediada, a questões epistemológicas. É insuficiente, nessa perspectiva, reduzir a obra de Acosta a seu significado "teórico", quando este simplesmente não pode ser separado dos objetivos imediatos aos que o autor se propunha. Sendo assim, mostra-se de grande interesse, através de outra obra importante de Acosta, seu De procuranda Indorum salute, ${ }^{51}$ analisar a inserção política do autor e seu conjunto de propostas com relação às demais figuras que atuavam no contexto específico do Vice-Reino do Peru no último quarto do século XVI. Observa-se, desde logo, o caráter essencialmente prescritivo dessa obra ao levar-se em consideração que se trata de uma espécie de "manual" destinado prioritariamente ao público missionário. Aliás, é sintomático o fato de que muitos de seus trechos tenham sido diretamente transpostos para os decretos emanados pelo III Concílio Provincial de Lima (1582-83), do qual Acosta participara na condição de teólogo consultor. ${ }^{52}$

Entre os diversos temas tratados ao longo dos seis livros que compõem a obra, é de grande interesse pensar a forma pela qual Acosta aborda a questão da "servidão natural", problema cujas implicações concretas mostravam-se muito latentes no contexto ibérico. É interessante analisar, primeiramente, a posição adotada pelo autor no âmbito das disputas que se travavam entre aqueles que

America Review, v. 14, n. I, 2005, p. 55-81.

${ }^{51}$ Para facilitar a leitura, essa obra será sempre referida como De procuranda.

52 ACOSTA, José de. De procuranda, op. cit., v. 2, p. 355-492. Los decretos del Sancto Concilio Provincial celebrado en la Ciudad de los Reyes del Perú en el año de 1583. In: VARGAS UGARTE, Rubén. Los Concilios Limenses (1551-1772). Lima: Tipografia Ravaga, 1951-1954 [1583], v. 1, p. $313-375$. 
defendiam, a partir de uma determinada tradição aristotélica, ${ }^{53}$ a possibilidade de escravização dos índios devido à sua compleição "naturalmente servil" e aqueles que se contrapunham a essa perspectiva, de modo a não imputar qualquer predisposição dos americanos à submissão. Ambos os grupos concordavam, todavia, que os maus hábitos praticados pelos indígenas americanos mostravam-se profundamente deletérios à sua cristianização. Ora, no âmbito dessa disputa, Acosta retoma toda uma tradição para indicar, conforme o fizera Francisco de Vitoria, que a compleição bárbara dos americanos decorreria não de um dado natural e imutável, mas de uma condição derivada de seus costumes e de sua educação. ${ }^{54}$ Como consequência dessa constatação há toda uma preocupação expressa por parte do autor no sentido de enfatizar a necessidade prévia de promover um "processo civilizador" dada a necessidade de tornar os índios "antes homens e depois cristãos" ${ }^{55}$ Esse tópico da argumentação de Acosta aponta para o íntimo relacionamento que têm nas suas reflexões o elemento civil e o elemento religioso. Tal posição, em termos imediatos (fato que lhe causará problemas junto ao poder imperial), abre caminho para uma legitimação do exercício de poder indireto da Igreja sobre instâncias de jurisdição temporal. ${ }^{56}$

O tema acima referido da decadência dos bárbaros pode ser enriquecido a partir dessas considerações. Basta lembrar o significado "positivo" derivado do esquecimento de um passado comum pra compreender o íntimo nexo existente entre língua balbuciante e "anomia política" ${ }^{57} \mathrm{Se}$, de sua parte, o esquecimento remete à perda de uma origem comum, resta absolutamente significativo em relação a isso o fato de que a rudeza das instituições civis nativas (suas formas de governo, suas leis) deve-se antes às falhas de sua convivência na civitas. Importante retomar aqui as distinções estabelecidas por Acosta com relação aos diversos graus de barbárie já indicados: se os chineses representam o mais alto grau de refinamento no interior de uma condição bárbara em termos linguísticos,

\footnotetext{
${ }^{53}$ No âmbito dessa disputa fica clara a existência de diversas tradições aristotélicas, cujos desdobramentos teóricos chegam a conclusões bastante distantes entre si, ainda que igualmente respaldadas na autoridade do filósofo grego.

${ }^{54}$ ACOSTA, José de. De procuranda, op. cit. VITORIA, Francisco de. Relectio de indis. Carta magna de los indios. 450 aniversario, 1539-1989. Madri: Consejo Superior de Investigaciones Cientificas, 1989 [1539]. Importante notar que a argumentação de Acosta não coincide com aquela delineada por Bartolomé de Las Casas, tendo em vista o caráter mais ameno e conciliador com o qual trata a matéria. PAGDEN, Anthony, op. cit., p. 146.

${ }^{55}$ ACOSTA, José de. Historia, op. cit., p. 359.

${ }^{56}$ ACOSTA, José de. De procuranda, op. cit., v. 1. Nesse ponto, Acosta retoma outra importante formulação de Vitoria. VITORIA, Francisco de, op. cit., p. 111.

${ }^{57}$ Fala-se em "anomia" sem qualquer referência à sociologia moderna; "política" por sua vez é referida aqui no seu significado coevo, isto é, em relação com o policiamento dos costumes.
} 
isso é diretamente associado à sua refinada vida civil. ${ }^{58}$ Tal fato aponta para uma valorização da imutabilidade da lei (sua "previsibilidade") e da estabilidade de um poder soberano local (questão evidenciada através da existência de magistrados).

Nesse ponto específico, a oposição marcada por Acosta entre "chichimecas" e mexicas no contexto mesoamericano joga um papel fundamental na economia expositiva delineada pelo autor. ${ }^{59} \mathrm{O}$ fato de utilizar-se de referências internas à tradição narrativa mexica é, aliás, sintomática nesse sentido. ${ }^{60} \mathrm{~A}$ construção dessas figuras antitéticas é significativa na medida em que evidencia o quadro operativo dessa distinção de graus. Por um lado, "chichimecas" são retratados como as figuras-tipo da selvageria: nômades, habitam em cavernas e bosques, isolados do trato humano, vivem como que em manadas, unicamente voltados para a busca por comida, alimentam-se de animais repugnantes e apenas ensaiam qualquer tipo de comunicação. ${ }^{61} \mathrm{~A}$ ação do Diabo, a quem é reputada a migração asteca em direção ao Vale Central Mexicano, permite que estes tomem o lugar dos "chichimecas" e instaurem ali um exemplo de civilização bárbara relativamente elevada: primeiramente, tratam-se de povos finalmente sedentários, cuja convivência se dá no espaço privilegiado de Tenochtitlán; tanto sua religião organizada em torno de idolatrias, quanto seu governo tirânico são indicativos de uma vida cívico-religiosa em vias de desenvolvimento; seus artifícios linguístico-mnemônicos, enfim, completam o quadro atribuindo-lhes uma profundidade histórica relativamente alta levando-se em consideração que se tratam de populações ágrafas. ${ }^{62}$ As consequências desse fato são claras aos olhos de Acosta: se mexicas e peruanos estavam como que predispostos à ação missionária, dada a existência ali de instituições com relação às quais a missão deveria agir como realização ulterior de "potencialidades naturais", entre os selvagens a missão se depara com o trabalhoso papel de instituir os próprios elementos mínimos do civil e do religioso, numa perspectiva que tem por horizonte a civitas dei agostiniana. ${ }^{63}$

${ }_{58}$ ACOSTA, José de. De procuranda, op. cit., v. 1, p. 62-63.

${ }^{59}$ ACOSTA, José de. Historia, op. cit., p. 358-401. Note-se que a tardia missão jesuítica na Nova Espanha teve como uma de suas prioridades o trabalho missionário junto às populações ditas "chichimecas".

${ }^{60}$ Eduardo Natalino dos Santos propõe a existência de alguma continuidade entre as narrativas mexicas e sua apropriação posterior por Durán/Tovar/Acosta. Dessa forma, Acosta reflete em sua narrativa da história mesoamericana um eixo explicativo "mexicocêntrico". SANTOS, Eduardo Natalino dos, op. cit.

${ }^{61}$ ACOSTA, José de. Historia, op. cit., p. 358-360.

${ }^{62}$ Idem, p. 360-401.

${ }^{63}$ AGNOLIN, Adone, op. cit., p. 130-134. 
Essa "queda do homem natural" vivenciada, em última instância, por todas as populações bárbaras, é explicada por Acosta a partir da ausência de uma vida política. ${ }^{64} \mathrm{O}$ que apenas fica sugerido pela caracterização geral acima apontada é que o acidente histórico que levou os povos americanos ao nomadismo contribuiu para a sua progressiva regressão rumo ao isolamento, à dispersão, à incomunicabilidade, ao esquecimento. É como consequência de uma educação no interior desses costumes que Acosta apresenta a instabilidade, a precariedade e o desequilíbrio das instituições cívico-religiosas nativas. Contudo, os casos mexica e inca são preciosos, para o autor, no sentido de apontar para uma possibilidade "natural" de perfectibilidade. De fato, a ignorância acerca da verdade revelada (e, portanto, do direito divino) opõe-se como barreira unicamente transponível pela mediação missionária. Todavia, as obras de Acosta apontam para uma abertura relativa à legitimação (que não incorre necessariamente em aceitação) de um "direito natural" nativo (intuído pela razão humana) paralelo àquela "religião natural". É a partir dessa legitimidade de parte das instituições nativas que o missionário deve operar uma função propriamente conversora. Assim sendo, dada a degeneração perante um passado esquecido, oferece-se a possibilidade de um aperfeiçoamento levado a cabo pelos próprios bárbaros a partir de sua racionalidade. É, todavia, com relação àquelas populações que se mostram obstinadas em sua condição bárbara que, ao mesmo tempo, Acosta propõe uma civilização que seja operada sob tutela missionária.

\subsection{Soberania e sacramentos}

O Vice-Reino do Peru é um interessante laboratório no que se refere às questões acima referidas. Para entender tal fato é necessário, contudo, compreender as diversas mudanças que se operaram na região no último quarto do século XVI. Primeiramente, portanto, observa-se a aceleração do processo de constituição de uma soberania política da Coroa de Castela sobre a região. Se bem que o processo remonte especialmente à década de 1550, a figura do vice-rei Francisco de Toledo é de suma importância no sentido de operar uma centralização crescente do poder em torno dos funcionários reais. ${ }^{65}$ Aliás, é possível observar, no conjunto das possessões castelhanas, esse processo de fortalecimento das prerrogativas imperiais em detrimento de conquistadores, encomenderos e vecinos que, todavia, mantêm

\footnotetext{
${ }^{64}$ PAGDEN, Anthony, op. cit., p. 8-9.

${ }^{65}$ ESTENSSORO FUCHS, Juan Carlos. Del paganismo a la santidad, op. cit., p. 179-184.
} 
ainda muito de sua influência. ${ }^{66}$ Ainda assim, é importante levar em consideração a especificidade peruana nesse processo, qual seja, a herança de uma trajetória de conquista particularmente traumática, marcada por agudas disputas entre facções de conquistadores. ${ }^{67}$ Ao mesmo tempo, as dificuldades opostas da parte dos índios à presença europeia na região prosseguiram até o final do século. Foi justamente sob o governo de Toledo que se efetivou a definitiva "pacificação" do último reduto de resistência inca (1572); até então, o controle sobre as terras altas na região mostrava-se extremamente precário ${ }^{68}$ Por outro lado, os chiriguanos, população "baixa" da encosta oriental dos Andes, mostravam-se um empecilho à dominação castelhana numa região fundamental ao Vice-Reino, o Alto Peru. ${ }^{69}$ Por fim, somese a tais ameaças à soberania espanhola a vulnerabilidade da região com relação a ataques de piratas estrangeiros, que se lançaram diversas vezes sobre Lima. ${ }^{70}$

Toda essa preocupação com a garantia da soberania castelhana sobre a região é certamente potencializada pelo pico de produção de prata conhecido por parte das minas de Potosí. Num momento em que as jazidas localizadas ao norte da Nova Espanha apenas começavam a apresentar níveis de produção vultosos, a produção peruana representava um papel chave como base da engenharia financeira montada para sustentar a política belicosa promovida na Europa por Felipe II. Nesse contexto, a presença chiriguana, por exemplo, se mostrava particularmente ameaçadora, na medida em que lhes era relativamente fácil bloquear as rotas que ligavam Potosí a Lima. ${ }^{71}$

É sob as vicissitudes representadas por esse contexto de profundas mudanças que interessa recuperar a relativa afinidade existente entre os (distintos) projetos esposados pela Coroa e pela Companhia de Jesus. Se, de fato, é possível falar num compartilhamento de códigos denotativos da alteridade, também a

${ }^{66}$ ELLIOTT, John Huxtable. Spain and America in the sixteenth and seventeenth centuries. In: BETHELL, Leslie (org.). The Cambridge history of Latin America. Cambridge: Cambridge University Press, 1984, v. 1, p. 287-339.

${ }^{67}$ BERNAND, Carmen e GRUZINSKI, Serge. História do Novo Mundo: da descoberta à conquista, uma experiência europeia, 1492-1550. São Paulo: Editora da Universidade de São Paulo, 1997 [1991], p. 534-538.

${ }^{68}$ WACHTEL, Nathan La vision des vaincus: les indiens du Pérou devant la conquête espagnole, 1530-1570. Paris: Gallimard, 1977 [1971], p. 257-276.

${ }^{69}$ WACHTEL, Nathan. The Indian and the Spanish conquest. In: BETHELL, Leslie (org.), op. cit., v. 1. p. 207-248. As primeiras incursões de combate a essas populações foram promovidas por Francisco de Toledo, sem sucesso.

${ }^{70}$ Marginal no que se refere aos recursos desviados sob essa modalidade, a pirataria é mais significativa no contexto peruano por sua visibilidade. ELLIOTT, John Huxtable. Spain and America, op. cit.

${ }^{71}$ WACHTEL, Nathan. The Indian and the Spanish conquest, op. cit. 
prática política efetivada é passível de aproximações. ${ }^{72}$ Exemplar desse fato é a própria relação travada entre Acosta e Toledo, iniciada logo quando da chegada do primeiro ao Peru. Essa complementaridade institucional e epistemológica entre Coroa e jesuítas sugere a análise da "virada ortodoxa" ocorrida no último quarto do século $\mathrm{XVI}^{73} \mathrm{em}$ perspectiva com o estabelecimento de uma soberania imperial no plano político. Nesse sentido, os sacramentos aparecem como figura disciplinar privilegiada dessa relação.

Acosta dedica um importante livro de seu De procuranda ao tema dos sacramentos, em que sugere a forma pela qual eles deveriam ser aplicados para surtir um efeito desejável. ${ }^{74}$ No que se refere a esse tema é importante recuperar a íntima relação entre suas propostas e as decisões emanadas pelo Concílio de Trento (1545-1563). Se bem que em suas sessões a participação de personagens advindas dos contextos missionários extra-europeus fosse extremamente reduzida, a recepção das disposições tridentinas foi especialmente importante em terras de missão. No caso peruano, a realização do II e do III Concílio Provincial de Lima (respectivamente em 1567-68 e 1582-83) atendeu expressamente à necessidade de aplicar a legislação da Reforma Católica à realidade local. ${ }^{75}$ Ora, se, por um lado, a preocupação tridentina com a ortodoxia doutrinal se revela na ênfase posta sobre o instrumento catequético, por outro lado, a normatização dos sacramentos é outra preocupação central em Trento. ${ }^{76}$ Com essa reafirmação do conjunto ritual católico pretende-se tornar visíveis as marcas de uma fé que pode, a partir de então, se distinguir claramente, seja perante o campo protestante, seja com relação às "heresias rurais" europeias. ${ }^{77}$ Com relação a tal proposição o clero

72 Aproximações estas que não tornam menos efetivas as importantes diferenças reveladas por essas duas instituições. Basta referir que a política dos vice-reis procede a um esvaziamento do poder das ordens regulares, a partir da vinda para a região de numerosos padres seculares. ELLIOTT, John Huxtable. Spain and America, op. cit. COELLO DE LA ROSA, Alexandre, op. cit., p. 55-56.

${ }^{73}$ ESTENSSORO FUCHS, Juan Carlos. Les pouvoirs de la parole - prédication au Pérou: de l'evangelisation à l'utopie. In: Annales: Histoire, Sciences Sociales. n. 6, 1996, p. 1.225-1.257.

74 ACOSTA, José de. De procuranda, op. cit., v. 2, p. 355-492.

${ }^{75}$ Los decretos del Sancto Concilio Provincial. op. cit. Contudo, é importante observar que a reivindicação da autoridade tridentina não se desdobrou numa aderência completa aos seus decretos por parte dos Concílios Limenses. Ao contrário, observa-se por parte do clero peruano uma aplicação instrumental e seletiva das resoluções do Concílio de Trento, ao menos no século XVI.

${ }^{76}$ AGNOLIN, Adone. op. cit. p. 150-188. PROSPERI, Adriano. O missionário. In: VILLARI, Rosário (org.). O homem barroco. Lisboa: Editorial Estampa, 1995 [1988], p. 143-171. O tema dos sacramentos permite enfatizar o caráter fundamentalmente "ortoprático" do catolicismo, historicamente baseado antes numa organização ritual que num corpo doutrinal. GASBARRO, Nicola, op. cit., p.67-78.

${ }^{77}$ Importante indicar o importante papel de Acosta no processo inquisitorial do dominicano Francisco de la Cruz (1572-1578). Acosta critica nele justamente a defesa da ideia de fides implicita, 
americano mostra-se profundamente receptivo, na medida em que entrevê ali uma possibilidade de efetivar uma evangelização que já se revelara difícil.

Acosta opera no interior dessas questões e suas propostas com relação aos sacramentos presentes no De procuranda são extremamente sintomáticas quanto a isso. De fato, alguns sacramentos passam a ser vistos como instrumentos privilegiados de disciplina dos costumes nativos. O sacramento do matrimônio, por exemplo, é objeto da preocupação de Acosta na medida em que permite "reduzir" a instituição nativa aos quadros aceitáveis da família nuclear europeia, de modo a combater o incesto, a poligamia e o concubinato que marcariam a realidade local. ${ }^{78}$ Mas são os papéis destinados por Acosta aos sacramentos do batismo e da penitência que colocam questões mais sugestivas no que se refere a esse papel renovado conferido ao ritual.

O sacramento do batismo fora o instrumento missionário privilegiado quando da primeira evangelização em diversos contextos. ${ }^{79}$ Contudo, esse entusiasmo inicial é logo deixado de lado frente aos contínuos insucessos missionários; paralelamente, o tema da "inconstância" dos bárbaros assume um papel cada vez mais central nos relatos. ${ }^{80}$ Frente a essa limitação inerente ao batismo, cuja presença pontual na vida do neófito é insuficiente para arraigá-lo a sua nova fé, Acosta propõe um novo modelo batismal. A mudança consiste basicamente no condicionamento do batismo à demonstração de conhecimentos prévios por parte dos neófitos acerca da doutrina. ${ }^{81}$ Assim, a partir desse ponto de vista, o trabalho catequético aparece como momento prévio e necessário para se evitar a inconstância do indígena na fé. Em outras palavras, a aquisição de um conhecimento profundo (mesmo que sintético) abriria espaço a um enraizamento dos conteúdos doutrinais.

Contudo, essa sutil modificação no procedimento batismal não pode ser inteiramente compreendida sem que se faça a devida referência à proposta avançada por Acosta no que tange à esfera da penitência. Assim, se o batismo põe em jogo

a partir da qual os sacramentos perdem seu valor denotativo com relação à fides. ACOSTA, José de. De procuranda, op. cit., v. 2, p. 212-219.

78 ACOSTA, José de. De procuranda, op. cit., v. 2, p. 458-485.

${ }^{79} \mathrm{O}$ caso mais emblemático é sem dúvida aquele representado pelos franciscanos da Nova Espanha. DUVERGER, Christian. La conversión de los indios de Nueva España. México: Fondo de Cultura Económica, 1993 [1987].

${ }^{80}$ O tema da "inconstância" aparece já naquelas cartas de Manuel da Nóbrega que refletem uma posição mais cautelosa frente ao otimismo que dominou o início da missão brasileira. Cf., por exemplo, NÓBREGA, Manuel da. Diálogo da conversão dos gentios do p. Manuel da Nóbrega. In: LEITE, Serafim Soares (org.). Monumenta brasiliae. Roma: Monumenta Historica Societatis Iesu, 1957, v. II, p. 317-345.

${ }^{81}$ ACOSTA, José de. De procuranda, op. cit., v. 2, p. 362-381. 
uma consciência expressa através da "vontade" (projetada para o futuro) e do "arrependimento" (voltado para o passado), a confissão opera a partir desse mesmo campo. Sua vantagem relativa, porém, reside no fato de que se trata aqui de um ritual renovado constantemente.$^{82} \mathrm{~A}$ sistematização do pecado realizada nesse nível ritual institui ao mesmo tempo, portanto, uma interiorização do medo de pecar e uma disciplina social: uma consciência individual profundamente interligada à "contabilização dos pecados". ${ }^{83}$ Ora, essa economia do medo e da punição institui o nexo disciplinar fundamental em relação à constituição de uma soberania imperial.

Mas a parcial identidade entre essa "virada ortodoxa" e a constituição da soberania imperial se expressa ainda num outro campo. Para além do instrumento sacramental, Acosta oferece como sugestão disciplinar a proposta de constituição de aldeamentos fixos. ${ }^{84} \mathrm{~A}$ "redução" da vida comum a uma disciplina urbana permitiria, na opinião do autor, submeter a vida familiar a uma vigilância pública por parte da comunidade, de modo a coibir os pecados. Além disso, a divisão das casas em função de famílias nucleares serviria à disciplina da vida sexual no foro privado. Concretamente, Acosta teve um importante papel quando da organização do primeiro aldeamento fixo jesuíta, em Juli, no Alto Peru. Note-se que essa política é levada a cabo de modo concomitante à reorganização de populações indígenas dispersas em pueblos, política patrocinada por Toledo. ${ }^{85}$ Ao mesmo tempo, é importante recuperar a historicidade dos conceitos de "missão" e de "redução", que se encontram intimamente ligados às redes de circulação de informações das diversas experiências missionárias. A política jesuítica no Peru permite que se reconstitua uma genealogia que desembocará na formação das "reduções" paraguaias, nos séculos XVII e XVIII. Em outro sentido, é interessante notar que a política de fixação dos indígenas sugerida por Acosta, bem como suas propostas com relação ao batismo, ressoam preocupações caras à experiência missionária na América portuguesa, à qual ele teve acesso por meio das cartas de Manuel da Nóbrega. ${ }^{86}$

A constituição de aldeamentos fixos oferece, assim, uma saída concreta para o problema, analisado anteriormente, da carência de vida civil entre as populações

\footnotetext{
${ }^{82}$ A frequência da confissão é, aliás, uma preocupação cara ao Concílio de Trento. AGNOLIN, Adone, op. cit., p. 179-184.

${ }^{83}$ DELUMEAU, Jean. La péché et la peur: la culpabilisation en Occident (XIIIe-XVIIIe siècles). Paris: Fayard, 1990 [1983]. BARTHES, Roland. Sade, Fourier, Loyola. Paris: Seuil, 1971.

${ }^{84}$ ACOSTA, José de. De procuranda, op. cit., v. 1, p. 538-541.

${ }^{85}$ TOLEDO, Francisco de. Disposiciones gubernativas para el virreinato del Peru. Sevilha: Escuela de Estudios Hispano-Americanos; Consejo Superior de Investigaciones Cientificas; Monte de Piedad y Caja de Ahorros de Sevilla, 1986-1989 [1569-1581], v. 1, p. 1-39.

${ }^{86}$ ACOSTA, José de. De procuranda, v. 2, p. 42-45. AGNOLIN, Adone, op. cit., p. 342-421.
} 
bárbaras. Trata-se, portanto, do espaço por excelência onde se instituir um efetivo "processo civilizador", que, no limite, pode ser realizado através do uso da força: uma "tirania honesta". Diga-se de passagem, este último é um termo utilizado pelo próprio Acosta quando da descrição das populações mais distanciadas de um ideal de "policiamento dos costumes" ${ }^{87}$ Essa imagem, contudo, deve ser compreendida na íntima relação entre projeto missionário e "redução" teórica que caracteriza a "dupla marginalidade" de Acosta. Isso porque a "tirania honesta", enquanto proposta de ação civilizadora por parte do missionário, pressupõe uma comparação analógica fundada na unicidade do gênero humano. A "redução" dos bárbaros à vida civil opera-se com base no seu prévio enquadramento no quadro categorial e cultural europeu, o que se efetiva através da extensão do poder explicativo das "instituições teóricas" tradicionais: "ídolo", "religião", "diabo", "superstição", "feitiçaria". Contudo, efeito secundário desse processo de generalização do código religioso, observa-se uma progressiva "laicização" dessa linguagem denotativa da alteridade, que vai se abrindo, aos poucos, para uma paulatina substituição da religião por outro código de generalização mais abrangente representado pelo direito. ${ }^{89}$

\section{Referências bibliográficas}

ACOSTA, José de. De procuranda Indorum salute. Madri: Consejo Superior de Investigaciones Cientificas, 1984-1987 [1588]. 2 vs.

ACOSTA, José de. Historia natural y moral de las Indias. En que se tratan de las cosas notables del cielo, elementos, metales, plantas y animales dellas y los ritos, y ceremonias, leyes e gobierno de los indios. México: Fondo de Cultura Económica, 2006 [1590].

AGNOLIN, Adone. Jesuitas e selvagens: a negociação da fé no encontro catequéticoritual americano-tupi (séculos XVI-XVII). São Paulo: Humanitas; Fapesp, 2007.

BARTHES, Roland. Sade, Fourier, Loyola. Paris: Seuil, 1971.

BERNAND, Carmen e GRUZINSKI, Serge. História do Novo Mundo: da descoberta à conquista, uma experiência europeia, 1492-1550. São Paulo: Editora da Universidade de São Paulo, 1997 [1991].

BETHELL, Leslie (org.). The Cambridge history of Latin America. Cambridge: Cambridge University Press, 1984, v. 1.

${ }^{87}$ ACOSTA, José de. Historia, op. cit.

${ }^{88}$ O conceito de "laicização" presta-se a inúmeros equívocos. Remeto nesse sentido à sua utilização por parte de Nicola Gasbarro. GASBARRO, Nicola Maria, op. cit.

${ }^{89}$ Não se trata do objeto específico dessa pesquisa; apenas pretende-se destacar a crescente utilização do direito enquanto código privilegiado a abarcar a "realidade". GASBARRO, Nicola Maria, op. cit. 
COELLO DE LA ROSA, Alexandre. Más allá del Incario: imperialismo e historia em José de Acosta, SJ (1540-1600). In: Colonial Latin America Review, v. 14, n. I, 2005, p. 55-81.

Los decretos del Sancto Concilio Provincial celebrado en la Ciudad de los Reyes del Perú en el año de 1583. In: VARGAS UGARTE, Rubén. Los Concilios Limenses (1551-1772). Lima: Tipografia Ravaga, 1951-1954 [1583] v. 1, p. 313-375.

DELUMEAU, Jean. La péché et la peur: la culpabilisation en Occident (XIIIe-XVIIIe siècles). Paris: Fayard, 1990 [1983].

DUVERGER, Christian. La conversión de los indios de Nueva España. México: Fondo de Cultura Económica, 1993 [1987].

ELLIOTT, John Huxtable. The Old World and the New: 1492-1650. Cambridge: Cambridge University Press, 1970.

ELLIOTT, John Huxtable. Spain and America in the sixteenth and seventeenth centuries. In: BETHELL, Leslie (org.). The Cambridge history of Latin America. Cambridge: Cambridge University Press, 1984, v. 1, p. 287-339.

ESTENSSORO FUCHS, Juan Carlos. Les pouvoirs de la parole - prédication au Pérou: de l'evangelisation à l'utopie. In: Annales: Histoire, Sciences Sociales n. 6, 1996, p. 1.225-1.257.

ESTENSSORO FUCHS, Juan Carlos. Del paganismo a la santidad. La incorporación de los indios del Perú al catolicismo. 1532-1750. Lima: Instituto Francés de Estudios Andinos; Instituto Riva-Aguero, 2003 [1998].

GASBARRO, Nicola Maria. Missões: a civilização cristã em ação. In: MONTERO, Paula (org.). Deus na aldeia: missionários, índios e mediação cultural. São Paulo: Globo, 2006, p. 67-109.

GLIOZZI, Giuliano. Adam et le Nouveau Monde. La naissance de l'anthropologie comme idéologie coloniale: des généalogies bibliques aux théories raciales (1500-1700). Lecques: Thééthète Éditions, 2000 [1977].

GRUZINSKI, Serge e BERNAND, Carmen. História do Novo Mundo: da descoberta à conquista, uma experiência europeia, 1492-1550. São Paulo: Editora da Universidade de São Paulo, 1997 [1991].

LEITE, Serafim Soares (org.). Monumenta brasiliae. Roma: Monumenta Historica Societatis Iesu, 1957, v. II.

MONTERO, Paula (org.). Deus na aldeia: missionários, índios e mediação cultural. São Paulo: Globo, 2006.

NÓBREGA, Manuel da. Diálogo da conversão dos gentios do p. Manuel da Nóbrega. In: LEITE, Serafim Soares (org.). Monumenta brasiliae. Roma: Monumenta Historica Societatis Iesu, 1957 [1557], v. II, p. 317-345.

O'GORMAN, Edmundo. La invención de América: investigación acerca de la estructura histórica del Nuevo Mundo y del sentido de su devenir. México: Fondo de Cultura Económica, 2003 [1958].

O'GORMAN, Edmundo. Prólogo. In: ACOSTA, José de. Historia natural y moral de 
las Indias. En que se tratan de las cosas notables del cielo, elementos, metales, plantas y animales dellas y los ritos, y ceremonias, leyes e gobierno de los indios. México: Fondo de Cultura Económica, 2006 [1962], p. XV-CXI.

PAGDEN, Anthony. The fall of natural man: the American Indian and the origins of comparative ethnology. Cambridge: Cambridge University Press, 1999 [1982].

PROSPERI, Adriano. O missionário. In: VILLARI, Rosário (org.). O homem barroco. Lisboa: Editorial Estampa, 1995 [1988], p. 143-171.

SANTOS, Eduardo Natalino dos. Deuses do México indígena: estudo comparativo entre narrativas espanholas e nativas. São Paulo: Palas Athena, 2002.

TOLEDO, Francisco de. Disposiciones gubernativas para el virreinato del Peru. Sevilha: Escuela de Estudios Hispano-Americanos; Consejo Superior de Investigaciones Cientificas; Monte de Piedad y Caja de Ahorros de Sevilla, 1986-1989 [1569-1581]. 2. vs.

VARGAS UGARTE, Rubén. Los Concilios Limenses (1551-1772). Lima: Tipografia Ravaga, 1951-1954, v. 1.

VILLARI, Rosário (org.). O homem barroco. Lisboa: Editorial Estampa, 1995 [1988].

VITORIA, Francisco de. Relectio de indis. Carta magna de los indios. 450 aniversario, 1539-1989. Madri: Consejo Superior de Investigaciones Cientificas, 1989 [1539].

WACHTEL, Nathan. La vision des vaincus: les indiens du Pérou devant la conquête espagnole, 1530-1570. Paris: Gallimard, 1977 [1971].

WACHTEL, Nathan. The Indian and the Spanish conquest. In: BETHELL, Leslie (org.). The Cambridge history of Latin America. Cambridge: Cambridge University Press, 1984, v. 1, p. 207-248.

Recebido: 09/03/2010 - Aprovado: 24/02/2011. 
